\title{
Seroprevalence of hepatitis $B$ and $C$ viruses and risk factors in HIV infected children at the felgehiwot referral hospital, Ethiopia
}

\author{
Bayeh Abera ${ }^{1 *}$, Yohanes Zenebe ${ }^{1}$, Wondemagegn Mulu' ${ }^{1}$ Mulugeta Kibret ${ }^{2}$ and Getachew Kahsu ${ }^{3}$
}

\begin{abstract}
Background: Liver hepatitis due to Hepatitis B (HBV) and hepatitis C virus (HCV) co-infection is the leading cause of morbidity and mortality in HIV infected children and it is more severe in resource poor settings. Data on seroprevalence of HBV and HCV among HIV infected children are scarce in Ethiopia. This study was conducted to determine seroprevalence and risk factors of HBV and HCV and its effect on liver enzyme among HIV-positive children aged 18 months to 15 years attending the paediatric HIV care and treatment clinic at Felege Hiwot referral hospital, Ethiopia.
\end{abstract}

Methods: A cross-sectional study was conducted in May, 2014. Demographic and risk factors were collected using a structured questionnaire. Hepatitis B surface antigen (HBsAg) and anti-HCV antibodies were detected using an enzyme linked immunosorbent assay (ELISA). Alanine aminotransferase (ALT) levels were determined. The results were analyzed using descriptive and logistic regression.

Results: A total of 253 HIV positive children, boys (52.5\%) and girls (47.5\%) took part in the study. The median age of the children was 11 years. Overall, 19 (7.5\%) of HIV infected children were positive either for HBsAg or anti-HCV antibodies. The seroprevalence of HBV and HCV were $2.0 \%$ and 5.5\%, respectively. All HBsAg positive children were in older age groups (11-15years). Seroprevalence of HCV was higher in children from urban (7.7\%) than rural (1.2\%) residents $(P=0.02)$. Overall, $29(12.1 \%)$ of children had elevated ALT. Of these, $31.5 \%$ were from HBsAg or anti-HCV antibody positive children whereas $9.8 \%$ were from hepatitis $B$ or $C$ virus negative children $(P=0.001)$. Multivariate logistic regression showed that being positive for HBsAg or anti-HCV antibody (AOR: 4.7(95\% Cl: 1.5-13.5) was significantly associated with elevated ALT.

Conclusion: HBV and HCV co-infections are common in HIV positive children. In HIV positive children, HBV and $\mathrm{HCV}$ co-infection were associated with elevate ALT. Routine screening for HBV and HCV in HIV infected children should be implemented.

Keywords: HBV, HCV, HIV, ALT, Children

\section{Background}

Co-infection of HIV positive population with hepatitis B ( $\mathrm{HBV})$ and hepatitis $\mathrm{C}(\mathrm{HCV})$ is a global problem owing to the shared routes of transmission. Prevention and control of these infections are more challenging in subSaharan Africa [1]. In Ethiopia, 1.3 million people live with HIV ( $78 \%$ adults and $22 \%$ children $<14$ years) [2].

\footnotetext{
* Correspondence: bayeabera15@gmail.com

'Department of Medical Microbiology, Parasitology and Immunology, College of Medicine and Health Sciences, Bahir Dar University, Bahir Dar, Ethiopia

Full list of author information is available at the end of the article
}

Although, the exact prevalence of HIV in children in Ethiopia is not known, approximately, 154,084 children live with HIV in 2014 and 16,000 children were receiving ART in 2013 [2].

Globally, over 350 and 170 million people are chronically infected with $\mathrm{HBV}$ and $\mathrm{HCV}$, respectively $[3,4]$. In sub-Saharan Africa, the overall prevalence of HBV and HCV co- infection in HIV infected people were $15 \%$ and $7 \%$, respectively [5]. In Ethiopia, virtually, all data on sero-prevalence of $\mathrm{HBV}$ and $\mathrm{HCV}$ have been documented from adults $[6,7]$. 
Both HBV and HCV infections cause acute and chronic liver infection with potential to liver cirrhosis and hepatocellular carcinoma [8]. Studies showed that HBV and $\mathrm{HCV}$ infections are the major causes of morbidity and mortality in HIV positive population related to liver cirrhosis and hepatocelular carcinoma $[9,10]$. The risk for development of liver cirrhosis is twice in $\mathrm{HCV} / \mathrm{HIV}$ co-infected than HIV mono infected groups [11]. A study conducted in Thailand showed that HBV and HCV co-infection accounted for increased mortality in ART-naïve patients [12].

WHO recommends screening for $\mathrm{HBV}$ and $\mathrm{HCV}$ before initiating ART [13]. However, in Ethiopia screening for $\mathrm{HBV}$ and $\mathrm{HCV}$ in $\mathrm{HIV}$ positive individuals is not practiced. For instance, a recent study in the same area reported 6.6\% HIV prevalence and 19.0\% HBV-HIVcoinfection in pregnant women, respectively [14]. There is a paucity of seroprevalence data on $\mathrm{HBV}$ and $\mathrm{HCV}$ in HIV infected children in Ethiopia. This study was therefore undertaken to determine seroprevalence and risk factors of HBVand $\mathrm{HCV}$ and its effect on liver ALT among HIV infected children aged 18 months to 15 years at Felege Hiwot referral hospital, Ethiopia.

\section{Methods}

\section{Study design and setting}

A hospital based cross-sectional study was conducted among HIV infected children at Felege hiwot referral hospital in May 2014. The hospital is one of the government-sponsored ART centers in Bahir Dar city. This hospital provides chronic HIV care (both pre-ART and ART) services. At the time of study, there were 1, 810 HIV positive children (810 Pre-ART and 1000 on ART) HIV at Felege hiwot pediatric ART clinic [personal communication]. The choice of ART was based on the Ethiopian ART guidelines. The three first line regimens generally comprised of [Tenofovir (TDF) + Lamivudine (3TC) + Nevirapine (NVP)/Efavirenz (EFV); or Zidovudine $(\mathrm{AZT})+3 \mathrm{TC}+\mathrm{NVP} / \mathrm{EFV}$; or Stavudine $(\mathrm{d} 4 \mathrm{~T})+3 \mathrm{TC}+\mathrm{NVP} / \mathrm{EFV}][15]$.

\section{Sample size and sampling technique}

Sample size was determined using Epi info version 7.0 (public domain soft ware www.cdc.gov) considering 95\% confidence level, marginal error of (5\%) and $10 \%$ prevalence of HBsAg [1]. Thus, sample size of 239 was calculated and10\% $(n=24)$ was added for nonrespondents. Random sampling technique was used to enroll the study participants using their registration logbook.

\section{Sample collection and processing}

A pre-tested questionnaire was used to collect data on demographic characteristics and associated risk factors such as sex, age, duration of ART, history blood transfusion, female genital mutilation (FGM), uvulectomy and residence of by face to face interviewing the childrens' parent. The presence of hepatitis $B$ surface antigens (HBsAg) and anti-HCV antibody (IgG and IgM) were detected on sera using ELISA according to the manufacturer's instruction (Linear Chemicals. Joaquim Costa, Barcelona, Spain). The catalytic activity of ALT (alanine amino transferase) was determined in serum using Beckman Coulter Synchron Clinical Systems auto lab analyzer (Beckman Coulter Inc. Fullerton, USA). Normal value for $\mathrm{ALT}$ at $37^{\circ} \mathrm{C}(0-40 \mathrm{IU} / \mathrm{L})$ was taken for both females and males. Laboratory quality controls were maintained by following standardized procedures during blood sample collection, storage and analytical process. Internal positive and negative controls were run alongside of the test.

\section{Statistical analysis}

Data was analyzed using the Statistical Package for Social Sciences (SPSS ${ }^{\bullet} 20$, USA). All explanatory variables with a $p$ value $\leq 0.2$ in the bivariate analysis were included in the multivariate logistic regression model to identify independent predictive variables. Odds ratio (OR) and 95\% confidence intervals $(\mathrm{CI})$ were calculated and the result was considered statistically significant at $\mathrm{p}<0.05$. Fisher's exact test was used to test categorical variables.

\section{Ethical consideration}

The study was ethically approved by the Research and Ethical Review Board of Bahir Dar University. Moreover, all parents of children gave written consent to participate in this study. Children positive for HBSAg and ant$\mathrm{HCV}$ antibody were reported to ART clinic pediatrician for further investigation and follow-up.

\section{Operational definition of liver toxicity degree according to $\mathrm{WHO}$}

Degree 0: the level of toxicity considered normal when its value is $>1.25 \times$ normal value of ALT.

Degree 1: the level of toxicity considered as weak when its value is $1.256-2.5 \times$ normal value of ALT.

Degree 2: the level of toxicity considered as moderate when its value is $2.6-5 \times$ normal value of ALT.

Degree 3: the level of toxicity considered as severe when its value is $5.1-10 \times$ normal value of ALT.

Degree 4: the level of toxicity considered as severe when its value is $>10 \times$ normal value of ALT.

\section{Results}

\section{Demographic characteristics}

A total of $253 \mathrm{HIV}$ infected children participated in the present study. Among these, 133 (52.5\%) were boys and $120(47.5 \%)$ were girls. The median age of the children 
was 11 years. Of these, $87.7 \%$ of children were on ART. The median length of time on ART was 48 months. During the study period, $96.7 \%$ of children were on the first line ART regimen. Demographic characteristics of hepatitis co-infection in children are summarized in Table 1.

\section{Seroprevalence of hepatitis B and C viruses}

Overall, 19 (7.5\%) HIV infected children were positive either for HBsAg or ant-HCV antibodies. The seroprevalence of $\mathrm{HCV}$ and $\mathrm{HBV}$ were $5.5 \%$ and $1.2 \%$, respectively. No study participant was positive for both HBV and $\mathrm{HCV}$. All HBsAg positive children were in older age groups between 11-15 years of age (Table 1). Hepatitis co-infected children were significantly older than their HIV-mono infected counter parts $(\mathrm{P}=0.01)$ (Table 2). The seroprevalence of $\mathrm{HCV}$ was higher in children from urban than rural residents $(\mathrm{P}=0.02)$. However, statistical significance difference was not observed between HBV prevalence and age groups. The results of the investigated potential risk factors are depicted in Table 2. Overall, significant association was not observed for seroprevalence of hepatitis and any of the investigated risk factors (Table 2).

\section{Associated risk factors}

According to WHO classification of HIV stage, $31.6 \%$ of children were either in stage 3 or 4 HIV (Table 2). In this study, $25(20.8 \%)$ of the girls had female genital mutilation (FGM) and 53 (21\%) had traditional uvulectomy. Nine participants $(3.5 \%)$ had history of blood transfusion. Among those with history of uvulectomy, $9.4 \%$ of them were positive for anti-HCV antibody. Among blood transfusion recipients, $1 / 9(1.1 \%)$ was positive for anti-HCV antibody. Conversely, none of them were positive for HBsAg.

\section{Alanine amino transferase (ALT)}

Among 222 children on ART, 29 (12.1\%) had elevated ALT compared to 2 (6.4\%) among 31 on pre-ART groups
(Table 3). The proportion of elevated ALT among HBsAg or anti-HCV antibody positive children was $31.5 \%$. But, 9.8\% elevated ALT was from those without hepatitis co-infection. Nineteen (7.5\%) of participants had grade 1 and 2 liver toxicity. Of these, only three children (1.2\%) developed grade 2 liver toxicity. However, none of the study participants developed either grade 3 or 4 liver toxicity. Multivariate logistic regression analysis showed that being positive for $\mathrm{HBsAg}$ or anti-HCV antibody (AOR: 4.7(95\%CI: 1.5-13.5) was significantly associated with elevated ALT (Table 3).

\section{Discussion}

The present study demonstrated the prevailing seroprevalence of HBV and HCV in HIV infected children for the first time in Ethiopia. The antiretroviral therapy (ART) program in Ethiopia has significantly reduced morbidity and mortality in HIV infected individuals [16]. However, liver diseases from HBV and HCV co-infection may have negative impact on the success of ART program particularly in resource poor settings where facilities are limited for HBV and HCV testing and monitoring.

The HBsAg prevalence in HIV infected children in this study $(2.0 \%)$ is comparable with studies in Thailand (3.3\%), Democratic Republic of Congo (1.6\%) and Tanzania $(1.2 \%)$ and $[12,17,18]$. In contrast, it is lower compared to other studies in Africa. For instance, 5.8\% to $15.9 \%$ of $\mathrm{HBV} / \mathrm{HIV}$ sereoprevalence in HIV infected children was reported in West Africa [19-22]. Moreover, it is far lower than the HBsAg prevalence $(11.2 \%$ to $19.0 \%$ ) among HIV positive adults in the same study area in Bahir Dar [14,23]. To our knowledge, there are no data on HBsAg in HIV positive children in Ethiopia therefore we could not compare our results directly with similar age groups.

This low HBsAg prevalence in children cannot be attributed to $\mathrm{HBV}$ vaccine program since all study

Table 1 Seroprevalence of HBV and HCV and demographic characteristics among HIV infected children, North West Ethiopia, 2014

\begin{tabular}{|c|c|c|c|c|}
\hline Characteristics & Total sample & $\begin{array}{c}\mathrm{HBSAg} \\
\text { positive } \mathrm{N}(\%)\end{array}$ & $\begin{array}{l}\text { HCV antibody } \\
\text { positive } \mathrm{N}(\%)\end{array}$ & $\begin{array}{l}\text { Total } \\
\text { N (\%) }\end{array}$ \\
\hline \multicolumn{5}{|l|}{ Sex } \\
\hline Female & 120 & $2(1.7)$ & $4(3.3)$ & $6(5.0)$ \\
\hline Male & 133 & $3(2.2)$ & $10(7.5)$ & $13(9.7)$ \\
\hline Total & 253 & $5(2.0)$ & $14(5.5)$ & $19(7.5)$ \\
\hline \multicolumn{5}{|c|}{ Age group (years) } \\
\hline$\leq 5$ & 14 & $0(0)$ & $1(7.1)$ & $1(7.1)$ \\
\hline $6-10$ & 103 & $0(0)$ & $4(3.9)$ & $4(3.9)$ \\
\hline $11-15$ & 136 & $5(3.6)$ & $9(6.6)$ & $14(10.2$ \\
\hline Total & 253 & $5(2.0)$ & $14(5.5)$ & $19(7.5)$ \\
\hline
\end{tabular}


Table 2 Association of local risk factors for HBV and HCV co-infection in HIV infected children, North West, Ethiopia, 2014

\begin{tabular}{|c|c|c|c|c|c|}
\hline Variables & Total sample & HBSAg positive $\mathrm{N}(\%)$ & $P$ value & HCV seropositive $N(\%)$ & $P$ value \\
\hline \multicolumn{6}{|l|}{ Sex } \\
\hline Girls & 120 & $2(1.7)$ & 0.56 & $4(3.3)$ & 0.14 \\
\hline Boys & 133 & $3(2.2)$ & & $10(7.5)$ & \\
\hline Mean age (years) & $11.1 \pm 3.4^{* *}$ & $13.4 \pm 2.7$ & 0.001 & $12.5 \pm 4.1$ & 0.01 \\
\hline \multicolumn{6}{|l|}{ Residence } \\
\hline Urban & 169 & $2(1.2)$ & 0.16 & $13(7.7)$ & 0.02 \\
\hline Rural & 84 & $3(3.5)$ & & $1(1.2)$ & \\
\hline \multicolumn{6}{|l|}{ Uvulectomy } \\
\hline Yes & 53 & $0(0)$ & NA & $5(9.4)$ & 0.16 \\
\hline No & 200 & $5(2.5)$ & & $9(4.3)$ & \\
\hline \multicolumn{6}{|l|}{ Blood transfusion } \\
\hline Yes & 9 & $0(0)$ & NA & $1(1.1)$ & NA \\
\hline No & 244 & $5(2.0)$ & & $13(5.3)$ & \\
\hline \multicolumn{6}{|l|}{ FGM } \\
\hline Yes & 25 & $0(0)$ & NA & $1(4.0)$ & NA \\
\hline No & 228 & $5(2.2)$ & & $13(5.7)$ & \\
\hline \multicolumn{6}{|l|}{ WHO staging } \\
\hline 1 and 2 & 173 & 4 & 0.41 & 9 & 0.46 \\
\hline 3 and 4 & 80 & 1 & & 5 & \\
\hline
\end{tabular}

**: Mean age for mono HIV infection; NA: not applicable, FGM: female genital mutilation.

Table 3 Bivariate and multivariate logistic regression for associated variables for elevated ALT

\begin{tabular}{|c|c|c|c|}
\hline Variables & $\begin{array}{c}\text { Elevated } \\
\text { ALT N (\%) }\end{array}$ & $\begin{array}{c}\text { Univariate } \\
\text { COR } 95 \% \mathrm{Cl}\end{array}$ & $\begin{array}{c}\text { Multivariate } \\
\text { AOR }(95 \% \mathrm{Cl})\end{array}$ \\
\hline \multicolumn{4}{|l|}{ Sex } \\
\hline Female $(n=120)$ & $10(9.0)$ & $0.5(0.22-1.30)$ & $0.36(0.03-2.7)$ \\
\hline male $(n=133)$ & $19(14.3)$ & & \\
\hline \multicolumn{4}{|l|}{ ART status } \\
\hline On ART $(n=222)$ & $27(12.2)$ & $1.6(0.35-7.3)$ & $2.0(0.43-6.8)$ \\
\hline Not on ART $(n=31)$ & $2(6.4)$ & 1.0 & \\
\hline \multicolumn{4}{|l|}{ Residence } \\
\hline Urban $(n=169)$ & $16(9.4)$ & 1.0 & \\
\hline Rural $(n=84)$ & $13(15.4)$ & $0.51(0.22-1.2)$ & $3.2(1.2-8.2)^{*}$ \\
\hline \multicolumn{4}{|l|}{ HBSAg } \\
\hline Positive $(n=5)$ & $3(60)$ & $1.9(0.22-18.1)$ & $0.49(0.06-4.3)$ \\
\hline Negative $(n=248)$ & $26(10.5)$ & 1.0 & \\
\hline \multicolumn{4}{|l|}{ Anti-HCV Ab } \\
\hline Positive $(n=14)$ & $3(21.4)$ & $2.3(0.4-10.0)$ & $1.6(0.22-11.5)$ \\
\hline Negative $(n=239)$ & $26(5.8)$ & 1.0 & \\
\hline \multicolumn{4}{|l|}{ Anti-HCV or HBsAg } \\
\hline Positive $(n=19)$ & 6 & $3.2(1.4-14.2)$ & $4.7(1.5-13.5)^{* *}$ \\
\hline Negative $(n=234)$ & 23 & 1.0 & \\
\hline
\end{tabular}

*: P value 0.01 and **P value $=0.001 ;$ ART: antiretroviral therapy; AOR: adjusted odds ratio; COR: crud odds ratio; anti-hepatitis C virus antibodies; Cl: confidence interval. 
participants had not been vaccinated. The other possible factors may be occult hepatitis $B$ virus infection (OBI) because OBI is common in HIV infected children [24]. Furthermore, the effect of the potential anti-hepatitis $\mathrm{B}$ virus agent lamivudine (3TC) may be attributed to low prevalence in $\mathrm{HBV}$. Because, $87.7 \%$ of $\mathrm{HIV}$ infected participants were on ART that contain 3TC [15]. The investigated local risk factors such as female genital mutilation (FGM), uvuloctomy, blood transfusion and WHO HIV staging had no significant association with prevalence of HBsAg. The only associated risk factor for HBsAg positive was age of the participants $(\mathrm{P}=0.001)$ (Table 2). Likewise, studies in a Nigeria and USA reported that HBV co-infection was associated in children aged 11-15 years [20,25].

The seroprevalence of $\mathrm{HCV}$ in this study (5.5\%) conforms to the estimated prevalence of $\mathrm{HCV}$ in Africa (5.3\%), which is the highest in the world [26]. It is also comparable with reports from Nigeria (6.8\%) [27]. Comparison was not possible in Ethiopian context owing to lack of HCV seroprevalence data in HIV infected children. Although, the study population is different, previous studies in Ethiopia reported 4.5 to 9.2\% HCV seroprevalence in HIV positive adults $[28,29]$. In contrast, in other studies $13.5 \%$ and $10.3 \%$ seroprevalence of $\mathrm{HCV}$ were reported in HIV-infected children [16,30].

In this study, local risk factors for hepatitis co-infection were investigated hence $20.8 \%$ of girls had female genital mutilation (FGM). This is similar with the national data which stated that $25 \%$ of $0-14$ years old children had FGM [31]. But, in our study none of them were found to be positive for either of the hepatitis virus markers. Although, statistical significant association was not noted, children who have had history of traditional uvulecyomy had higher HCV seroprevalnce (9.4\%) than their counterparts without history of uvulecyomy (4.3\%). In this study, seroprevalence of $\mathrm{HCV}$ was higher in children from urban (7.7\%) than rural children $(1.2 \%)$ $(\mathrm{P}=0.02)$. The other investigated potential risk factors were not significantly associated with seroprevalence of HCV or HBV (Table 2).

Regards to ALT, liver toxicity was mild since none of the participants developed either grade 3 or 4 liver toxicity. However, $7.5 \%$ of children developed grade 1 and 2 of liver toxicity. ART usage had no significant association with elevated ALT. Similarly, in Tanzanian children no association was documented between usage of ART and elevated ALT [18]. This may be elucidated by duration of ART and in this study $96.7 \%$ of children were on the first line ART regimen during the study period. Using multivariate logistic regression analysis, children positive either for $\mathrm{HBsAg}$ or anti-HCV antibody had 4.7 times more risk of elevated ALT (Table 3).
This study was not without limitation thus detecting of active replication of $\mathrm{HCV}$ and its genotype in anti$\mathrm{HCV}$ patients may be more accurate than antibody test but were not possible due to the limitations of working in resource poor settings [32]. However, these data showing a high rate of $\mathrm{HCV}$ co-infection highlight the urgent need for more detailed characterization $\mathrm{HCV}$ by HCV RNA testing and HCV genotyping. Thus, preliminary information on $\mathrm{HCV}$ has paramount importance to plan resources to avail the emerging curative treatment for $\mathrm{HCV}$ using direct acting antiviral agents (DAAs) that are associated with high (>95\%) cure rates.

\section{Conclusion}

Overall seroprevalence of hepatitis $\mathrm{B}$ and $\mathrm{C}$ viruses in HIV positive children were high. Hepatitis co-infections in HIV positive children were associated with elevated ALT. Therefore, routine screenings for $\mathrm{HBV}$ and $\mathrm{HCV}$ in HIV positive children need to be in place.

\section{Competing interests}

The authors declare that they have no competing interest.

\section{Authors' contributions}

BA: Contributed from inception of the research question to design, analysis, interpretation and preparation of the manuscript. YZ: edited and analyzed the data. WM involved in acquisition of data and edited the manuscript MK: contributed to data analysis and manuscript preparation. All authors have critically reviewed and approved the final manuscript.

\section{Authors' information}

BA is associate professor of Medical Microbiology, in the department of Medical microbiology, Immunology and Parasitology, at College of Medicine and Health Sciences, Bahir Dar University, Ethiopia. YZ is lecturer in the department of Medical microbiology, Immunology and Parasitology, at College of Medicine and Health Sciences, Bahir Dar University, Ethiopia. WM, is assistant professor in the department of Medical microbiology, Immunology and Parasitology, at College of Medicine and Health Sciences, Bahir Dar University, Ethiopia. MK, is associate professor of applied Microbiology Department of Biology, Science College, Bahir Dar University, Ethiopia. GK, is Bench scientist at Bahir Dar Regional Health Research Laboratory Center, Amhara region, Ethiopia.

\section{Acknowledgments}

This research was financed by Bahir Dar University. We also acknowledge Bahir Dar Regional Health Research Laboratory for allowing the use of laboratory equipment.

\section{Author details}

${ }^{1}$ Department of Medical Microbiology, Parasitology and Immunology, College of Medicine and Health Sciences, Bahir Dar University, Bahir Dar, Ethiopia. ${ }^{2}$ Department of Biology, Science College, Bahir Dar University, Bahir Dar, Ethiopia. ${ }^{3}$ Bahir Dar Regional Health Research Laboratory Center, Bahir Dar, Ethiopia.

Received: 16 September 2014 Accepted: 18 November 2014 Published: 25 November 2014

\section{References}

1. Matthews CP, Geretti AM, GoulderP JR, Klenerman P: Epidemiology of and impact of HIV coinfection with hepatitis $B$ andHepatitis $C$ viruses in Sub-Saharan Africa. J Clin Virol 2014, 61:20-33.

2. Federal Ministry of Health (FMOH): Country Progress Report on HIV/AIDS Response. Addis Ababa, Ethiopia: National HIV/AIDS Prevention and Control Office; 2012 
3. Alter MJ: Epidemiology of viral hepatitis and HIV co-infection. $J$ Hepatol 2006, 44:S6-S9.

4. Chu CJ, Lee SD: Hepatitis B virus/hepatitis C virus coinfection: epidemiology, clinical features, viral interactions and treatment. J Gastroenterol Hepatol 2008, 23:512-520.

5. Barth RE, Huijgen Q, Taljaard J, Hoepelman Al: Hepatitis B/C and HIV in sub-Saharan Africa: an association between highly prevalent infectious diseases. A systematic review and meta-analysis. Int J Infect Dis 2010, 14:e1024-e1031.

6. Dessie A, Abera B, Wale F: Seroprevalence of major blood-borne infections among blood donors at Felege Hiwot referral hospital, northwest Ethiopia. Ethiop J Health Dev 2007, 21:68-69.

7. Gelaw B, Mengistu Y: Prevalence of HBV, HCV and malaria parasites among blood donors in Amhara and Tigray regional states. Ethiop Health Dev 2007, 22:3-7.

8. Gunn RA, Murray PJ, Ackers ML, Hardison WG, Margolis HS: Screening for chronic hepatitis $B$ and $C$ virus infections in an urban sexually transmitted disease clinic - rationale for integrating services. Sex Transm Dis 2001, 28:166-170.

9. Andreoni M, Giacometti A, Maida I, Meraviglia P, Ripamonti D, Sarmati L: HIV-HCV co-infection: epidemiology, pathogenesis and therapeutic implications. Eur Rev Med Pharmacol Sci 2012, 16:1473-1483.

10. Tien PC: Management and treatment of hepatitis $C$ virus infection in HIV-infected adults: recommendations from the veterans affairs hepatitis $C$ resource cemter program and national hepatitis $C$ program office. Am J Gastroenterol 2005, 100:2338-2354.

11. World Health Organization (WHO): Hepatitis C. Geneva: WHO; 2003.

12. Tsuchiya N, Pathipvanich P, Rojanawiwat A, Wichukchinda N, Koga I, Koga M, Auwanit W, Kilgore PE, Ariyoshi K, Sawanpanyalert P: Chronic hepatitis B and C co-infection increased all-cause mortality in HAART-naive HIV patients in northern Thailand. Epidemiol Infect 2012. 10.1017/ S0950268812002397 Cambridge University Press 2012.

13. World Health Organization (WHO): Antiretroviral Therapy for HIV Infection in Adults and Adolescents: Recommendations for a Public Health Approach. Geneva: WHO; 2010:1-63.

14. Zenebe H, Mulu W, Yimer M, Abera B: Sero-prevalence and risk factors of hepatitis $B$ virus and human immunodeficiency virus infection among pregnant women in Bahir Dar city, Northwest Ethiopia: a cross sectional study. BMC Infect Dis 2014, 14:118-125.

15. Federal Ministry of Health (FMO): Guidelines for Paediatric HIV/AIDS Care and Treatment in Ethiopia. Ethiopia: Federal HIV/AIDS Prevention and Control Office Federal Ministry of Health; 2008.

16. Assefa Y, Kiflie A, Tesfaye D, Hailemariam D, Kloos H, Edwin W, Laga M, Damme WV: Outcomes of antiretroviral treatment program in Ethiopia: retention of patients in care is a major challenge and varies across health facilities. BMC Health Serv Res 2011, 11:81-88.

17. Katabuka M, Mafuta ME, Ngoma AM, Beya PM, Yuma S, Aketi L, Kayembe K, Gini JR: Prevalence and risk factors for hepatitis $C$ virus, hepatitis $B$ virus and immunodeficiency virus in transfused children in Kinshasa. Indian $J$ Pediatr 2013, 80:659-662.

18. Telatela SP, Matee MI, Munubhi EK: Seroprevalence of hepatitis B and C viral co-infections among children infected withhuman immunodeficiency virus attending the paediatric HIV care and treatment centerat Muhimbili National Hospital in Dar-es Salaam, Tanzania. BMC Public Health 2007, 7:338. doi:10.1186/1471-2458-7-338.

19. Nwolisa E, Mbanefo F, Ezeogu J, Amadi P: Prevalence of hepatitis B co-infection amongst HIV infected children attending a care and treatment centre in Owerri, South-eastern Nigeria. Pan Afr Med J 2013, 14:89.

20. Anigilaje EA, Olutola A: Prevalence and clinical and immunovirological profile of human immunodeficiency virus-hepatitis B coinfection among children in an antirethroviral therapy prohramme in Benue State, Nigeria. ISRN Pediatr 2013, 2013: doi.org/10.1155/2013/932697.

21. Ikpeme EE, Etukudo O, Ekrikpo UE: Seroprevalence of HBV and HIV co-infection in children and outcomes following highly active antirethroviral therapy (HAART) in Uyo, South-south Nigeria. Afr Health Sci 2013, 13:955-961.

22. Jobarteh M, Malfroy M, Peterson I, Jeng A, Sarge-Njie R, Alabi A, Peterson K, Cotton $\mathrm{M}$, Hall $\mathrm{A}$, Jones SR, Whittle $\mathrm{H}$, Tedder $\mathrm{R}$, Jaye $\mathrm{A}$, Mendy $\mathrm{M}$ : Seroprevalence of hepatitis B and C virus in HIV-1 and HIV-2 infected Gambians. Virol J 2010, 7:230

23. Mulu W, Gidey B, Chernet A, Alem G, Abera B: Hepatotoxicity and associated risk factors in HIV-infected patients receiving antiretroviral therapy at
FelegHiwot referral hospital, Bahir Dar Ethiopia. Ethiop J Health Sci 2013, 23:217-226.

24. Tramuto F, Maida CM, Colomba GME, Carlo PD, Vitale F: Prevalence of occult hepatitis B virus infection in a cohort of HIV-positive patients resident in Sicily, Italy. Biomed Res Int 2013 2013. doi.org/10.1155/2013/859583.

25. Toussi SS, Abadi J, Rosenberg M, Levanon D: Prevalence of hepatitis B and C virus infections in children infected with HIV. HIV/AIDS 2007, 45:795-798.

26. Karoney MJ, Siika AM: Hepatitis $\mathrm{C}$ virus (HCV) infection in Africa: a review. Pan Afr Med J 2013, 14:44. doi:10.11604.

27. Eze JC, Ibeziako NS, Ikefuna AN, Nwokye IC, Uleanya ND, llechukwu GC: Prevalence and risk factors for hepatitis $C$ and human immunodeficiency virus coinfection among children in Enugu Nigeria. Afr J Infect Dis 2014, 8:5-8.

28. Ayele W, Nokes DJ, Abebe A, Messele T, Dejene A, Enquselassie F, Rinke de Wit TF, Fontanet AL: Higher prevalence of anti-HCV antibodies among HIV-positive compared to HIV-negative inhabitants of Addis Ababa, Ethiopia. J Med Virol 2002, 68:12-17.

29. Hadush H, Gebre-Selassie S, Mihret A: Hepatitis C virus and human immunodeficiency virus coinfection among attendants of voluntary counseling and testing centre and HIV follow up clinics in Mekelle Hospital. Pan Afr Med J 2013, 14:107. doi:10.11604/pamj.2013.14.107.

30. Muriuki BM, Gicheru MM, Wachira D, Nyamache AK, Khamadi SA: Prevalence of hepatitis $B$ and $C$ viral co-infections among HIV-1 infected individuals in Nairobi, Kenya. BMC Res Notes 2013, 6:363

31. UNICEF: Policy Brief: Abandoning FGM/C (Female Genital Mutilation/Cutting) in Ethiopia. UNICEF: Ethiopia; 2013.

32. Hoffmann CJ, Charalambous S, Martin DJ, Innes C, Churchyard GJ, Chaisson $R$, Grant $A D$, Fielding $K L$, Thio $C L$ : Hepatitis $B$ virus infection and response to antiretroviral therapy (ART) in a South African ART program. Clin Infect Dis 2008, 47:1479-1485.

doi:10.1186/1756-0500-7-838

Cite this article as: Abera et al:: Seroprevalence of hepatitis B and C viruses and risk factors in HIV infected children at the felgehiwot referral hospital, Ethiopia. BMC Research Notes 2014 7:838.

\section{Submit your next manuscript to BioMed Central and take full advantage of:}

- Convenient online submission

- Thorough peer review

- No space constraints or color figure charges

- Immediate publication on acceptance

- Inclusion in PubMed, CAS, Scopus and Google Scholar

- Research which is freely available for redistribution 